\title{
ORAL FACTORS IN ACCIDENTAL POISONING
}

\author{
BY \\ J. O. CRAIG \\ From the Royal Hospital for Sick Children, Glasgow
}

(RECEIVED FOR PUBLICATION MARCH 28, 1955)

Perverted appetite as a contributory cause of poisoning has previously excited comment but largely in connexion with poisoning by lead (Burrows, Rendle-Short and Hanna, 1951). Evidence of pica appears, usually without comment, in the cases of other poisoned children. For example, Davis and Hunt (1949) were unable to carry out successful gastric lavage on a child poisoned by an antihistamine as the stomach contained a heterogeneous mass of vegetable matter, and Prain (1950) found a plastic toy in the caecum of another poisoned child. However, exaggerated oral tendencies may not go as far as pica, and the present paper considers the degrees of oral abnormality to be found in children who have poisoned themselves.

\section{Material and Method}

The study is based on the histories of 31 consecutive cases of reputed poisoning seen by the writer at a children's hospital. Six of the cases have been excluded from the present series. Of these, one had been given poison in error by his parents, one poisoned himself while on holiday so that an adequate history could not be taken, and a history was not taken in another who was the child of a colleague. The remaining three, acting in concert, ate laburnum seeds. Their average age was over 5 years. Craig and Fraser (1953) pointed out that the average age of 15 children who ate laburnum seeds was $5 \frac{3}{4}$ years, whereas the average age of 500 children poisoned by all causes was under $2 \frac{3}{4}$ years. This great disparity in the age-groups suggests that the aetiology of laburnum poisoning differs from the aetiology of poisoning as a whole, and the laburnum cases have therefore been excluded from the present series. The remaining 25 cases represent the common poisoning pattern, both as regards age (average, 33 months) and the type of poison taken.

The mother was questioned when the child was about to leave hospital, the time when she was least likely to be confused or over-emotional. It is admitted that, when a mother was asked if her child had a tendency to put things in his mouth, she might have replied 'Yes' to show the poisoning as inevitable. On the other hand, it could be argued that she would reply 'No' to excuse her own lack of foresight in not keeping a poison from him. In practice, it was found that the mother replied promptly and did not seem to consider the significance of the questions before replying. It is believed that the case histories are valid.

As oral tendencies are common in the child population, an 'oral history' was taken from 25 controls. These were children aged from $1 \frac{1}{2}$ to 4 years (average, 31 months). They attended, or were siblings of those who attended, a surgical outpatient department. They do not necessarily represent a cross-section of the population, but they do represent that social grade from which came the poisoning cases.

\section{Case Histories}

As this study involves a subjective analysis of case histories, it is advisable to show in summary the main facts from which conclusions are drawn. Where the mother made a graphic statement, it is quoted verbatim.

Case P1. A boy, 3 years, took 'dexedrine' tablets. 'Him? He's full of soap and buttons for all I know.' In answering a follow-up letter, the mother wrote, 'I am still extracting safety-pins, buttons, screws from toothpaste tubes, etc., from his mouth at all times of day.' He had previously taken aspirin tablets.

Case P2. A girl, $1 \frac{1}{4}$ years, took barbiturate tablets. 'Terrible' for putting things in her mouth, 'bits off the floor or anything she can pick up.'

Case P3. A boy, 2 years, took aspirin tablets. He eats anything he sees in the way of clean food, but does not have pica, and does not show other unusual oral traits.

Case P4. A girl, $2 \frac{1}{4}$ years, took laxative pills containing strychnine. She had no exaggerated oral tendencies. 
Case P5. A girl, 5 years, took barbiturate tablets. She carried her feeding bottle about with her until the age of 3 years, and sucked it when not actively engaged in play. Had previously suffered from lupin poisoning, and had eaten rowan berries. A sister of Cases P6 and P7.

Case P6. A boy, $3 \frac{1}{2}$ years, took barbiturate tablets. A brother of Cases P5 and P7. 'I made sure I took his bottle away.' Takes two hours over each meal, 'Not because he doesn't like it, doctor. He always finishes it. He just chews and chews away at it.' Previous lupin poisoning, ${ }^{*}$ and had eaten rowan berries.

Case P7. A boy, $1 \frac{1}{4}$ years, took barbiturate tablets. A brother of Cases P5 and P6. His bottle also was 'taken away'. 'He eats bricks or earth or anything.' Had previously eaten rowan berries, but was not ambulant at the time of the lupin episode.

Case P8. A boy, $2 \frac{1}{2}$ years, took laxative tablets containing strychnine. No exaggerated oral traits.

Case P9. A boy, 13 years, took 'lysol'. 'He's put things in his mouth since he's walked. I've got to watch him all the time. It's usually things like crusts out of the gutter.' 'He's a greedy eater, you have to slow him down.' He was well-nourished, $3 \frac{1}{2} \mathrm{lb}$. over the expected weight for his age.

Case P10. A boy, 3 years, took 'thawpit'. Sucks his fingers whenever he finds anything soft or silky in his hand. From the description, this sounds like a conditioned reflex. For two weeks before the poisoning episode he had been taking a soft toy to bed with him. He used it as a breast substitute, holding it with both hands while sucking his thumb. Previously, he had a similar routine with a handkerchief.

Case P11. A girl, 2 years, took quinine tablets. She sucked a comforter from the age of 6 weeks. One week before the poisoning episode it was taken away from her, 'as she was getting worse instead of better'. Thereafter, she had 'never stopped eating', although previously a poor eater.

Case P12. A boy, $2 \frac{1}{2}$ years, took camphorated oil. He eats old bread off the floor, drains 'empty' bottles, and is much more prone to put things in his mouth than any of his three siblings.

Case P13. A girl, $2 \frac{1}{4}$ years, took 'black laxative tablets'. She has a tendency to put things in her mouth, and her parents had tried particularly to keep medicines from her as a result. She eats coal. She has a ritual with fluff picked off the floor. First, she stuffs it up her nose, then she pulls it down again and eats it. She is fascinated by squeezing snails and slugs.

Case P14. A girl, $2 \frac{1}{4}$ years, took chocolate laxative. She had no oral tendency until admitted to hospital shortly before the poisoning episode. While in hospital,

\footnotetext{
* As the writer has failed to find any written account of lupin poisoning, it seems pertinent to remark that the symptoms are very like those of laburnum poisoning.
}

an oral tendency appeared and became so marked that the ward sister specifically warned the mother about it. The symptom had persisted at home in the six weeks since discharge, and she had begun to eat sand.

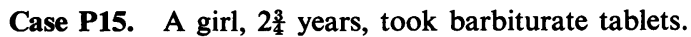
Very similar to Case P14. Since discharge from a fever hospital six weeks previously, she had taken to sucking her fingers by day and night, at least four at once. Simultaneously, she pulled and twisted her ears, which appeared normal on examination.

Case P16. A girl, $1 \frac{1}{2}$ years, took ferrous sulphate tablets. Oral tendencies not marked. Still takes feeding bottle to bed. Arrived in hospital at 10 p.m., alert, confident and sucking a bottle.

Case P17. A boy, 4 years, took barbiturate tablets. He had just been referred to hospital because of recurrent asthma. A highly-strung child, he is always sucking a thumb or fingers, always picking things up and putting them in his mouth.

Case P18. A girl, 10 years, took a dry-cleaning agent. The liquid was the colour of lemonade and in a lemonade bottle. The child asked permission to drink it. No unusual oral traits.

Case P19. A boy, 13 years, took turpentine substitute. No exaggerated oral traits.

Case P20. A boy, $2 \frac{1}{4}$ years, took travel sickness tablets (hyoscine). 'Is always biting at pencils and golf-balls.' He was nearly 2 years before relinquishing his bottle. His parents then gave him a hammer and told him to bash his bottle, which he did, apparently without regrets. For one month before the poisoning he had been demanding extra food between meals.

Case P21. A boy, 13 years, took turpentine substitute. 'I spend all my day watching him, I was glad to get rid of him when he was in hospital.' He is 'always after things' and will drink 'out of every bottle if he gets the chance.' Takes feeding bottle to bed with him. He also takes a doll and pretends to feed it with the bottle. Constantly nips, kicks and bites his mother.

Case P22. A boy, 13 years, took turpentine substitute. 'Out of hand,' but no exaggerated oral traits.

Case P23. A girl, $1 \frac{1}{2}$ years, took eardrops. Has to be checked frequently for putting things in her mouth, and in this respect is much worse than her two siblings.

Case P24. A boy, 5 years, took moth-balls. He has always been a thumb-sucker, and continues to suck it even in the daytime. He chews the corners of his shirt and pyjamas and is always asking for food. He is no longer allowed outside to play, as 'he eats old crusts out of pails' and has recently taken to eating bulbs which he has pulled up in the neighbours' gardens. Medicines have been kept rigidly in a locked cupboard. There is evidence in the early feeding history of a very strong oral tendency. 
TABLE 1

ORAL TRAITS IN CONTROL SERIES

\begin{tabular}{|c|c|c|c|c|c|}
\hline $\begin{array}{l}\text { Case } \\
\text { No. }\end{array}$ & Sex & $\begin{array}{l}\text { Age } \\
\text { (years and } \\
\text { months) }\end{array}$ & Oral Traits & $\begin{array}{l}\text { Severity of } \\
\text { Symptoms }\end{array}$ & $\begin{array}{l}\text { Classification } \\
\text { (see Table 2) }\end{array}$ \\
\hline $\begin{array}{ll}C & 1 \\
C & 2 \\
C & 3 \\
\text { C } & 4 \\
\text { C } & 5 \\
\text { C } & 6 \\
\text { C } & 7 \\
\text { C } & 8 \\
\text { C } & 9 \\
\text { C10 } & \\
\text { C11 } & \\
\text { C12 } & \\
\text { C13 } & \\
\text { C } 14\end{array}$ & $\begin{array}{l}\mathbf{M} \\
\mathbf{M} \\
\mathbf{F} \\
\mathbf{F} \\
\mathbf{M} \\
\mathbf{M} \\
\mathbf{M} \\
\mathbf{F} \\
\mathbf{F} \\
\mathbf{M} \\
\mathbf{F} \\
\mathbf{M} \\
\mathbf{M} \\
\mathbf{F}\end{array}$ & $\begin{array}{rr}1 & 8 \\
2 & 5 \\
2 & \\
3 & 11 \\
2 & 1 \\
2 & 3 \\
2 & 3 \\
2 & 11 \\
3 & 6 \\
3 & 8 \\
3 & 8 \\
2 & 4 \\
2 & 9 \\
2 & 2\end{array}$ & $\begin{array}{l}\text { Still sucks fingers, but only when tired } \\
\text { 'Fierce' at breast, sucks fingers at night, has 'breast substitute' sleep }\end{array}$ & Mild & $\mathbf{A}$ \\
\hline $\begin{array}{l}\text { C15 } \\
\text { C16 } \\
\text { C17 } \\
\text { C18 }\end{array}$ & $\begin{array}{l}\mathbf{F} \\
\mathbf{M} \\
\mathbf{M} \\
\mathbf{M}\end{array}$ & $\begin{array}{lr}1 & 8 \\
3 & 1 \\
1 & 11 \\
3 & 11\end{array}$ & $\begin{array}{l}\text { Sucks fingers by day } \\
\text { Sucks fingers when tired, 'breast substitute' sleep ritual till aged } 2 \text { years } \\
\text { Sucking movements of mouth in bed, no object put in mouth } \\
\text { Has reverted to night bottle, or comforter in bed, since birth of }\end{array}$ & $\begin{array}{l}\text { Moderate } \\
\text { Mild } \\
\text { Mild } \\
\text { Mild } \\
\text { Marked }\end{array}$ & B \\
\hline $\begin{array}{l}\text { C19 } \\
\text { C20 } \\
\text { C21 }\end{array}$ & $\begin{array}{l}\mathbf{M} \\
\mathbf{M} \\
\mathbf{M}\end{array}$ & $\begin{array}{ll}1 & 7 \\
2 & \\
2 & 5\end{array}$ & $\begin{array}{l}\text { Still has 'night bottle' } \\
\text { Puts small objects such as buttons in mouth } \\
\text { Sucks fingers by day, very large appetite, bites hard objects, people } \\
\text { and cushions }\end{array}$ & Mild & $\begin{array}{l}\mathbf{F} \\
\mathbf{D}\end{array}$ \\
\hline $\begin{array}{l}\text { C22 } \\
\text { C23 } \\
\text { C24 } \\
\text { C25 }\end{array}$ & $\begin{array}{l}\mathbf{F} \\
\mathbf{M} \\
\mathbf{M} \\
\mathbf{M}\end{array}$ & $\begin{array}{rr}2 & 8 \\
1 & 7 \\
3 & 10 \\
3 & 8\end{array}$ & $\begin{array}{l}\text { For one month, biting nails and gnawing large hard objects } \\
\text { Bites other children, their clothes and his cot } \\
\text { Pica till aged } 2 \text { years } \\
\text { Fierce feeder at bottle, pica till aged } 1 \frac{1}{2} \text { years, gnaws hard objects, } \\
\text { sucks fingers, has sleep ritual }\end{array}$ & $\begin{array}{l}\text { Mild } \\
\text { Moderate } \\
\text { Marked } \\
\text { Marked }\end{array}$ & $\begin{array}{l}\mathbf{C} \\
\mathbf{C} \\
\mathbf{G} \\
\mathbf{G}\end{array}$ \\
\hline
\end{tabular}

Case P25. A girl, 1 $\frac{1}{2}$ years, took moth-balls. Sister of Case P24. 'Puts things in her mouth when she sees her brother doing it.' When angry, she bites. 'She has a wicked little heart.'

\section{Controls}

The histories taken from the controls have been arranged in tabular form (Table 1). The numbering does not represent the order in which the histories were taken.

\section{Conclusions}

In comparing the results from controls and poisoning cases, both the type and the severity of the oral symptoms have been considered. In Table 2 the types are compared. The classification used is a utilitarian one, specifically designed to cover the cases in the present series, and making no claim to include all forms of oral abnormality.

The significance of oral traits in childhood is not yet fully understood, and it is thus impossible to differentiate in every case between normal, an exaggeration of normal and definitely abnormal oral symptoms. In the present series, cases in which it is doubtful whether the oral traits are exaggerated or not fall mainly into Category $B$. If these cases, except for $\mathrm{C} 18$, be regarded as normal, then 18 cases $(72 \%)$ in the control series are orally normal, as opposed to six poisoning cases $(24 \%)$. If they be regarded as exaggerations of normal, the figures
TABLE 2

TYPES OF ORAL SYMPTOM

\begin{tabular}{|c|c|c|c|}
\hline Classification & $\begin{array}{l}\text { Controls } \\
\text { (No. of } \\
\text { Cases) }\end{array}$ & $\begin{array}{l}\text { Poisonings } \\
\text { (No. of } \\
\text { Cases) }\end{array}$ & $\begin{array}{l}\text { Case Nos. in } \\
\text { Poisoning } \\
\text { Series }\end{array}$ \\
\hline A. No oral abnormality & 12 & 5 & $\begin{array}{l}\text { P4, P8, P18, } \\
\text { P19, P22 }\end{array}$ \\
\hline $\begin{array}{l}\text { B. Finger-sucking, suck- } \\
\text { ing movements of } \\
\text { mouth, sleep ritual at } \\
\text { night only } \ldots\end{array}$ & 7 & 1 & P16 \\
\hline $\begin{array}{l}\text { C. Aggressive use of } \\
\text { mouth, i.e., biting } \\
\text { people or hard objects }\end{array}$ & 2 & 1 & P25 \\
\hline $\begin{array}{l}\text { D. Group C, with traces } \\
\text { of Group F } \ldots\end{array}$ & 1 & 1 & P20 \\
\hline $\begin{array}{l}\text { E. Group F, with traces } \\
\text { of Group C } \ldots\end{array}$ & 0 & 1 & P17 \\
\hline $\begin{array}{l}\text { F. Use of mouth in self- } \\
\text { gratification, i.e., tast- } \\
\text { ing, overeating, gentle } \\
\text { sensation, sleep ritual } \\
\text { seen in daytime }\end{array}$ & 1 & 6 & $\begin{array}{l}\text { P3, P5, P6, } \\
\text { P10, P11, } \\
\text { P15 }\end{array}$ \\
\hline G. Pica $\quad$.. & 2 & 10 & $\begin{array}{l}\text { P1-2, } \\
\text { P9, } \\
\text { P21, }\end{array}$ \\
\hline Total & 25 & 25 & \\
\hline
\end{tabular}

become $48 \%$ and $20 \%$ respectively. At the other end of the scale, 10 poisoning cases $(40 \%)$ show pica compared with two cases $(8 \%)$ in the control series. Considering the rest of the classification, it appears 
that use of the mouth for self-gratification is found in a group of children where the incidence of pica is abnormally high. On the other hand, aggressive use of the mouth, for example, biting, is not particularly related to pica nor are the finger-sucking sleep rituals of early childhood.

A further comparison between the controls and the poisoning cases can be made on the basis of the severity of the oral symptoms. In some of the poisoning cases, e.g., P1 and P2, the oral history burst from the mother in a way which showed the symptoms to be severe, whereas the rather grudging admission of similar oral traits in some of the controls suggested that the symptoms were mild. In grading the control series the cases have been considered against a background of potential poisoning. Thus Case $\mathrm{C} 18$, not particularly striking when taken out of its context, has been graded as 'marked' as the child showed a reversion to a previous habit, as shown also in Cases P10, P14 and $P 15$. The oral symptoms in the poisoning group, as well as being more serious in type than in the control group, were more striking in their severity, as can be seen from Table 3 .

TABLE 3

SEVERITY OF ORAL SYMPTOMS

\begin{tabular}{|c|c|c|c|}
\hline Severity & $\begin{array}{l}\text { Controls } \\
\text { (No. of } \\
\text { Cases) }\end{array}$ & $\begin{array}{l}\text { Poisonings } \\
\text { (No. of } \\
\text { Cases) }\end{array}$ & $\begin{array}{l}\text { Case Nos. in } \\
\text { Poisoning } \\
\text { Series }\end{array}$ \\
\hline No symptoms . & 12 & 5 & P4, P8, P18-19, P22 \\
\hline Mild & 7 & 4 & P3, P16, P23, P25 \\
\hline Moderate & 2 & 1 & P1 \\
\hline Marked & 4 & 15 & $\begin{array}{l}\text { P2, P5-7, P9-15, P17, } \\
\text { P20-21, P24 }\end{array}$ \\
\hline
\end{tabular}

\section{Discussion}

Attention has so far been focused on the part played by exaggerated oral tendencies in producing poisoning in the early years. There is, however, further suggestive evidence to be obtained from the small group of five children (or six, if Case P16 be included), who poisoned themselves without evidence of abnormal oral traits. Three of these children took poison in liquid form, which is relatively uncommon. The other three took either pil. aloin co. or ferrous sulphate tablets, and it has been shown (Craig and Fraser, 1953; Craig, 1955) that the three poisons most dangerous to children at present are ferrous sulphate, the antihistamines and strychnine in the form of compound pills. Thus the three children who took the most dangerous poisons in the present series happened to show little or no oral abnormality, and came to no harm. This contrasts with Cases P5, P6 and P7, a family with strong oral tendencies, who were all in coma as the result of taking barbiturates, a poison which is relatively innocuous in childhood. The numbers involved in this comparison are too small for any valid conclusion to be reached, but the evidence can be combined with the more definite evidence previously obtained, and a theory concerning the aetiology of poisoning in childhood can be postulated.

It appears that children who poison themselves can be divided into two groups:

(1) A small group of normal, exploratory toddlers who may take poison, usually in the form of attractive tablets or liquid from a bottle, but who taste or chew the substance and, in the majority of cases, reject it before coming to harm.

(2) A large group of toddlers who show exaggerated oral traits, amounting to pica in about $50 \%$, and who poison themselves indiscriminately with tablets of any kind. Tablets attract them more than liquids, and, should they have access to attractive tablets such as ferrous sulphate, they would be particularly liable to bolt them in lethal quantities. The gourmet lives, the glutton dies.

This theory is, of course, complementary to accepted theories which stress the necessity of keeping poisonous substances away from children.

The exaggerated oral tendencies of the poisoned children were in many cases part of a widespread psychological disturbance. Three of the children came from a broken home; two others developed their symptoms while in hospital. In some cases the mothers' statements betray an unhappy parent-child relationship. However, a full psychological investigation was beyond the scope of the present study. Furthermore, an attempt to evaluate the feeding histories of the poisoned children was a failure, as the memory of the mother for the feeding details of two years before was too clouded for an accurate assessment to be made.

It should be clearly stressed that, even if one accepts the importance of the oral factor in poisoning, there is no good reason for relaxing general precautions against poisoning. Rather should they be intensified, particularly as the oral factor cannot be made the basis of propaganda for parents. On the other hand, it is highly desirable that anyone dealing with children should regard a poisoning episode not just as an accident that could happen to anyone, but as a significant milestone in the development of one particular child.

\section{Summary}

The case-histories of 25 poisoned children are reviewed, and it is found that there is a much higher 
incidence of exaggerated oral traits, often amounting to pica, in this group than in a control series.

It is stressed that this is no reason for relaxing the customary precautions against accidental poisoning in childhood.

The theory is put forward that there are two main groups of poisoned children. There is a large group, showing exaggerated oral traits, and a smaller group showing no such abnormality. The individual risk of death is probably greater in the former than in the latter group.
I am greatly indebted to Dr. F. H. Stone for his advice in the preparation of this paper, and to the physicians and surgeons of the Royal Hospitals for Sick Children in Edinburgh and Glasgow for granting me access to their patients.

\section{REFERENCES}

Burrows, N. F. E., Rendle-Short, J. and Hanna, D. (1951). Brit. med. J., 1, 329.

Craig, J. O. (1953). Archives of Disease in Childhood, 28, 475.

- (1955). Brit. med. J. To be published.

and Fraser, M. S. (1953). Archives of Disease in Childhood, 28, 259.

Davis, J. H. and Hunt, H. H. (1949). J. Pediat., 34, 358.

Prain, J. H. (1950). Brit. med. J., 1, 1375. 